\title{
Aspects of Satellite Delivered Mobile TV (SDMB)
}

\author{
Prof B. G. Evans, Dr P T Thompson, University of Surrey, England
}

\section{Abstract}

In this paper we review current satellite systems for radio and multimedia broadcast in the USA, Japan/Korea -Africa, Asia and the Middle East and in addition the various proposed systems for Europe. Many of these systems propose the use of the Complimentary Ground Component (CGC) for urban/ indoor coverage. We address aspects of the original SDMB as well as the ETSI/SDR and DVB-SH variants recognising that there is significant synergy between them. This work was conducted as part of the SatNEx Network Of Excellence.

\section{Index Terms}

SDMB, Satellite Digital Radio, Satellite Multimedia, ETSI-SDR, DVB-SH.

\section{INTRODUCTION}

Since the early development of the concept of Satellite Digital Multimedia Broadcasting (SDMB), which emerged from work in the area of Satellite Universal Mobile Telecommunications System (S-UMTS) [1], there has been an emergence of various satellite based service delivery systems that have the capability to convey multimedia material in various formats. During 2005-2007 these have undergone various degrees of convergence. The satellite radio area has received significant impetus in Europe with the establishment of European Telecommunications Standards Institute (ETSI) specifications for Satellite Digital Radio (SDR) [2] which is primarily aimed at the provision of digital radio but does not exclude video based multimedia. Meanwhile the Digital Video Broadcasting (DVB) project has been preparing specifications for DVB-SH (Satellite to Handheld) [3] a digital service focused upon video multimedia but does not exclude digital radio services. Consequently, there may be some potential ambiguity and confusion around the definition of SDMB.

In this work we cover all aspects of the original SDMB as well as the SDR and SH variants recognising that there is some synergy between them.

\section{REVIEW OF CURRENT AND PLANNED SYSTEMS}

a) Existing Systems

To introduce some background material regarding the wider definition of SDMB outlined above Table 1 briefly presents features of some existing systems along with references that can provide more extensive data.
Table 1: Overview of Existing Systems

\begin{tabular}{|c|c|c|c|c|}
\hline Name & $\begin{array}{l}\text { Start } \\
\text { Year }\end{array}$ & Service & Coverage & Comments \\
\hline $\begin{array}{c}\text { WorldSpace } \\
{[4]}\end{array}$ & 1998 & $\begin{array}{l}\text { Digital } \\
\text { Radio }\end{array}$ & $\begin{array}{l}\text { Africa, the } \\
\text { Middle } \\
\text { East and } \\
\text { Asia } \\
\end{array}$ & GEO \\
\hline XM Radio [5] & 2001 & $\begin{array}{l}\text { Digital } \\
\text { Radio }\end{array}$ & USA & $\begin{array}{c}2 \text { x15 } \mathrm{kW} \text {, GEO } \\
\text { satellites } \\
12.5 \mathrm{MHz} \\
(2332.5 \text { to } 2345.0 \\
\text { MHz) } \\
\text { approximately } 100 \\
\text { channels, } 70 \text { offer } \\
\text { music } \\
\end{array}$ \\
\hline Sirius [6] & 2002 & $\begin{array}{l}\text { Digital } \\
\text { Radio }\end{array}$ & USA & $\begin{array}{l}\text { Three satellites to } \\
\text { form an inclined } \\
\text { elliptical satellite } \\
\text { constellation. } \\
\text { Uses terrestrial } \\
\text { repeaters, Sirius } \\
\text { only planned for } \\
\text { roughly } 90 \\
\text { repeaters in } 45 \\
\text { urban areas. }\end{array}$ \\
\hline $\begin{array}{l}\text { MBSAT [7] } \\
\text { (Mobile } \\
\text { Broadcasting } \\
\text { Satellite) }\end{array}$ & 2004 & SDMB & Korea & $\begin{array}{c}\text { Service provided } \\
\text { by 'TU Media'. } 10 \\
\text { TV and } 50 \text { Radio } \\
\text { broadcast } \\
\text { programs. } \\
2000 \text { terrestrial } \\
\text { repeaters } \\
\end{array}$ \\
\hline $\begin{array}{c}\text { MobaHO [8], } \\
{[9]} \\
\text { (Mobile } \\
\text { Broadcasting } \\
\text { Service) }\end{array}$ & 2004 & SDMB & Japan & $\begin{array}{c}\text { Uses MBSAT } \\
\text { Stated to be the } \\
\text { world's first } \\
\text { satellite digital } \\
\text { multimedia } \\
\text { broadcasting } \\
\text { service for mobile } \\
\text { use outdoors, } \\
\text { indoors, and on } \\
\text { the go. } \\
\text { Provides services } \\
\text { throughout Japan } \\
\text { including some } 37 \\
\text { channels of audio } \\
\text { programs, eight } \\
\text { channels of video } \\
\text { programs, and } \\
\text { data information } \\
\text { services. }\end{array}$ \\
\hline
\end{tabular}


Considering the wider definition of SDMB outlined above, presents features of some planned systems along with references that can provide more extensive data.

Table 2: Overview of Planned Systems

\begin{tabular}{|c|c|c|c|c|}
\hline Name & Start Year & Service & Coverage & Comments \\
\hline $\begin{array}{l}\text { WORLDSPACE } \\
\text { Viatis [10] } \\
\end{array}$ & 2007 & Digital Radio & Europe & $\begin{array}{c}\text { European satellite digital radio (ESDR), uses terrestrial } \\
\text { repeaters } \\
\text { Geostationary Earth Orbit (GEO) satellites, } 100 \text { radio channels } \\
\end{array}$ \\
\hline $\begin{array}{l}\text { ARCHIMEDES which was } \\
\text { later called MEDIASTAR [11] }\end{array}$ & 1995 & Digital Radio & Europe & $\begin{array}{l}\text { Highly earth orbit (HEO) orbit } \\
\text { Failed to get adequate investment }\end{array}$ \\
\hline GLOBAL RADIO & 2002 & Digital Radio & Europe & $\begin{array}{c}3 \text { satellites in HEO orbit } \\
\text { Failed to get adequate investment }\end{array}$ \\
\hline EUROPA-MAX [12] & 2008 & SDMB & Europe & 3 satellites in HEO orbit \\
\hline ONDAS [13] & 2009 & Digital Radio & Europe & $\begin{array}{l}3 \text { satellites in HEO orbit, } \\
\text { May use Complementary Ground Component }\end{array}$ \\
\hline $\begin{array}{c}\text { NEMO [14] } \\
\text { (NEw MObile System) }\end{array}$ & 2010 & $\begin{array}{c}\text { Mobile } \\
\text { multimedia } \\
\text { delivery for } \\
\text { handheld and } \\
\text { vehicular uses }\end{array}$ & Europe & $\begin{array}{l}\text { GEO, Two satellites located on the geostationary satellite orbital } \\
\text { arc between } 43^{\circ} \mathrm{W} \text { and } 29 \mathrm{E}^{\circ} \\
\text { Uses Complementary Ground Component. }\end{array}$ \\
\hline $\begin{array}{l}\text { ALPHASAT [15] Proposed } \\
\text { SDMB Payload }\end{array}$ & 2010 & SDMB & Europe & $\begin{array}{c}\text { GEO } \\
\text { Note: proposal withdrawn }\end{array}$ \\
\hline $\begin{array}{l}\text { SOLARIS [16] } \\
\text { (Eutelsat/SES) }\end{array}$ & 2009 & SDMB & Europe & $\begin{array}{c}\text { GEO } \\
\text { S-Band payload on Eutelsat W2A, payload supplied by Alcatel- } \\
\text { Alenia }\end{array}$ \\
\hline $\begin{array}{c}\text { "Unlimited Mobile TV" } \\
{[17]}\end{array}$ & 2009 & SDMB & Various & MAESTRO end product. \\
\hline $\begin{array}{l}\text { ICO's Mobile Interactive } \\
\text { Media (MIM) [25] }\end{array}$ & 2008 & $\begin{array}{l}\text { Mobile } \\
\text { Interactive } \\
\text { Media }\end{array}$ & USA & Alpha trial planned \\
\hline
\end{tabular}

\section{c) Related EU Funded Research}

SDMB has been a key subject of EU funded R\&D projects which have been catalysts to significant developments in this field.

The EU R\&D SDMB Roadmap as shown in Figure 1 indicates the timeframe of the implementation of SDMB as foreseen by the researchers involved. It appears from a review of the currently planned systems that an additional 2 to 3 years may be required for realisation of the potential identified by the research.

In the following a brief outline of ONDAS, SOLARIS, the "Unlimited Mobile TV" (the end product of the MAESTRO project) and ICO's Mobile Interactive Media (MIM) are provided to gain an insight into the most likely systems for SDMB to be implemented in the near future.

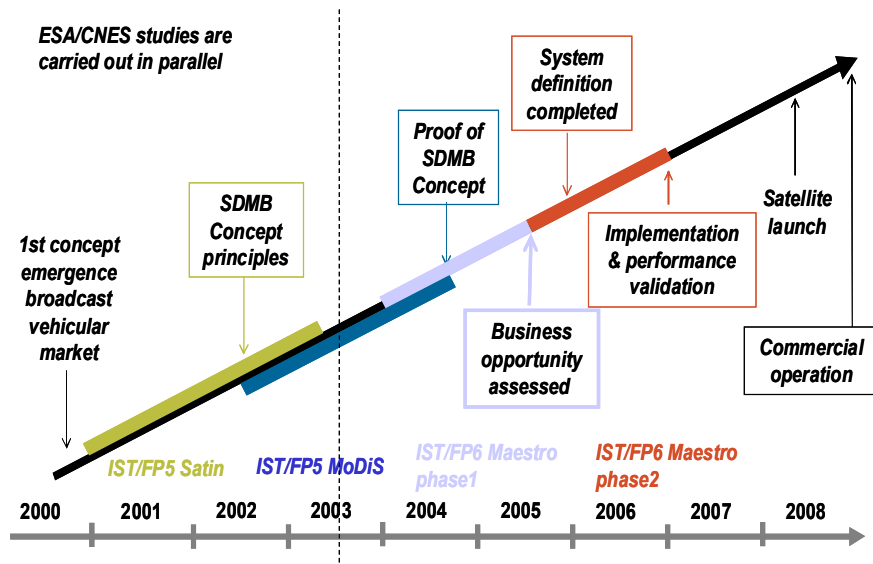

Figure 1: The SDMB roadmap covering SATIN, MODIS and MAESTRO 
The ONDAS satellite-based broadcasting system will be capable of transmitting high-quality digital multi-media (including DAB radio, mobile TV and data) content to fixed and mobile users over Europe. At the heart of the ONDAS system are the three identical ONDAS satellites each in a constant highly elliptical orbit (HEO) orbit around the earth. Each satellite will weigh around 5 metric tonnes and will carry enough fuel to provide at least 12 years of in-orbit operation. Twin solar arrays will provide $14 \mathrm{kWatts}$ of power throughout the life of the spacecraft and the use of a Beam Forming Network (BFN) and a $15 \mathrm{~m}$ deployable antenna will ensure that the footprint of each satellite is optimized for panEuropean coverage. Despite the high elevation angle advantage of the HEO orbit there will be some circumstances (e.g. in tunnels or in large cities) when signal blockages will become unavoidable, consequently ONDAS will deploy a limited number of terrestrial transmission repeaters to act as "gap-fillers".

The ONDAS satellites will be capable of broadcasting in any of the upper 14 MUXes which will ensure that the system will have the capacity to deliver hundreds of radio channels across Europe while retaining the flexibility to operate alongside other providers of DAB services in Europe without causing harmful interference, e.g. see Figure 2.

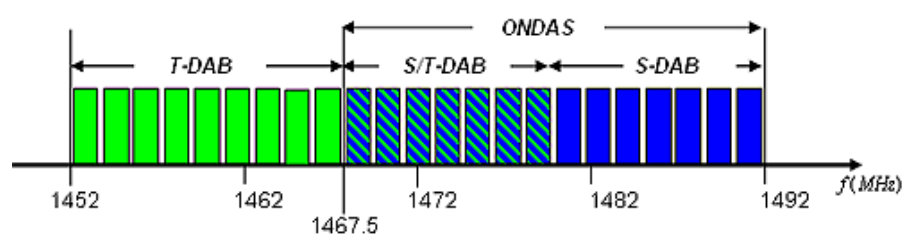

Figure 2: L-Band DAB spectrum allocation in Europe

\section{(2) SOLARIS}

This venture is a landmark in that it represents the first operation by either EUTELSAT or SES in S-Band (2170-2200 $\mathrm{MHz}$ ). It is indicated that terrestrial repeaters would be used in urban and suburban areas, with satellite providing the gapfiller. While the transmissions would be compatible with DVB-H, SES forecast a rapid standardisation some 18-24 months from now regarding the receiving units, this being confirmed by a matching announcement from Alcatel and Samsung who will manufacture the terminals.

SES quoted that the overall investment required to adapt the EUTELSAT W2A for SOLARIS is about $130 \mathrm{~m}$ Euro for the S-Band space segment payload plus modest additional infrastructural costs. S-Band capacity will be a maximum of 6 spot beams, but it is also possible to have just 4 beams, thereby boosting the output power. EUTELSAT have indicated that it is considering supplying up to 60 channels as part of the system, based on about 10 channels targeted for each market for satellite reception into rural areas. EUTELSAT have also indicated that when terrestrial repeater capacity is added the end result could be up to about 30 mobile-TV channels for each market. Alcatel is looking at providing its support to SES and EUTELSAT for a delivery of a "complementary system" recognising that at the moment DVB-H's deployment will occur around 2008 and SES and EUTELSAT think they will be ready with a launch date in a similar timeframe.

\section{(3) "Unlimited Mobile TV" (MAESTRO end product)}

MAESTRO was the latest in a series of European research projects relating to an SDMB satellite based solution for implementing a broadcast/multicast layer system complementary to the existing $2 \mathrm{G}$ and/or $3 \mathrm{G}$ cellular networks. The project was mainly focused on the use of $3 \mathrm{GPP}$ defined W-CDMA radio interface technology for both satellite and terrestrial component. However, the project also progressed to investigate the use of Orthogonal Frequency Division Multiplexing (OFDM) based radio interfaces based upon the DVB-H terminal. MAESTRO has contributed to the definition and validation of the most critical services, features and functions of satellite system architectures, so as to achieve a degree of integration with cellular network infrastructures.

Based on the promising MAESTRO project results, Alcatel created "Alcatel Mobile Broadcast", an Internal Venture whose remit is to promote and lead the development of a hybrid satellite/terrestrial mobile broadcast system called "Unlimited Mobile TV" ("Télévision Mobile Sans Limite" in French). This solution would be using an evolution of the DVB-H standard in the S-Band $(2 \mathrm{GHz})$, which is currently being standardized within the DVB Forum (DVB-SH). Thanks to the availability of the S-Band in European countries, the solution would deliver up to 45 mobile TV channels in broadcast mode anywhere in Europe at $256 \mathrm{~kb} / \mathrm{s}$ in average with a high image quality, including inside buildings for the areas covered by terrestrial repeaters. First elements of this solution could potentially be rolled out by 2008 for the terrestrial part of the system, followed by a full-scale deployment, which would include satellite, potentially by 2009.

\section{(4) ICO's Mobile Interactive Media (MIM)}

ICO Global Communications Limited announced that AlcatelLucent and Hughes Network Systems will develop key architecture and technology for use in ICO's alpha trial of Mobile Interactive Media (MIM) services, set for 2008. ICO MIM is a converged mobile media service which addresses a wide variety of consumers' entertainment and communication needs, based upon ICO's next-generation geostationary satellite (ICO G1) and the deployment of an Ancillary Terrestrial Component (ATC). Alcatel-Lucent has been chosen to supply the system architecture and design based on the mobile multimedia DVB-SH open standard. ICO MIM also will provide full-duplex, IP data communication services between customer devices and ICO satellite base station equipment using Hughes' proven ETSI standard GMR air interface technology, with a focus on Internet access, VoIP, and other data applications. In addition, Hughes will develop an integrated satellite terminal and antenna system to incorporate GMR and DVB-SH technologies, as well as a GPS receiver. 


\section{SYSTEM ARCHITECTURES}

\section{I) Overall System Architecture}

A generic architecture for SDMB is presented in Figure 3.

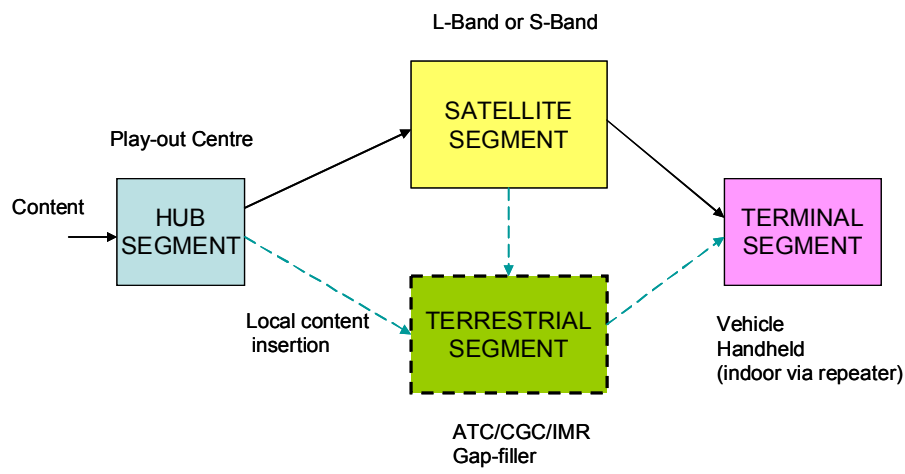

Figure 3: Generic SDMB Architecture

With regard to the Satellite Segment it is evident that both GEO and non-GEO configurations have their merits and disadvantages. In general GEO and HEO systems have been proposed but medium earth orbit (MEO) constellations are also possible candidates for SDMB services. The most popular frequency band for the satellite segment transmission to the terminal segment appears to be either the L-Band or the SBand.

The power and bandwidth constraints of the satellite segment strongly influence the choice of modulation and coding as well as the forward error correction (FEC) to be adopted. Furthermore, the nature of the signal fading and multipath conditions give rise for the need to adopt the use of interleaving to mitigate against these impairments. The use of Time Division Multiplexing (TDM) for single frequency carriers and OFDM for multiple carriers has been adopted for the ETSI SDR and DVB-SH standards.

The Terrestrial Segment is an optional component which is used to overcome loss of satellite signal due to shadowing and blockage. The terrestrial component can be fed from the satellite segment as indicated above or terrestrially, the latter enabling local content insertion. There are several descriptors used for the terrestrial segment:

- $\quad$ ATC - Ancillary Terrestrial Component

- CGC - Complementary Ground Component (European

- $\quad$ IMR - InterMediate Repeater

- Gap Filler.

The Terminal Segment performs the reception of the various broadcast signals In addition to the low layers processing, terminals will include adequate application layer decoders. It is envisaged that the terminals may be vehicle mounted, of a mobile handset nature or encapsulated in a PDA.

\section{AIR INTERFACES AND STANDARDS DEVELOPMENT}

Two candidate air interfaces have emerged in the last year or two. These are the ETSI SDR Standards and the DVB-SH Standards. Key aspects of these are the choice of FEC, use of interleaving, potential for time slicing, zapping time, ability to apply application layer FEC when appropriate plus the adoption of two different configurations, one for single carrier transmission and one for multi-carrier transmission. The FEC considered in both cases is turbo coding in line with the 3GPP2 turbo coding [24].

\section{(1) ETSI SDR}

Early work in the ETSI-SDR area was undertaken in the ITU and published as ITU-R BO1130-4. However, after careful analysis of applicable existing standards it was determined that none of them fulfil the functionalities now envisaged for satellite digital radio services and that a new standard was needed. Subsequently, ETSI TC SES has produced standards and other deliverables for Satellite Digital Radio (SDR) systems. An SDR system enables broadcast to fixed and mobile receivers through satellites and complementary terrestrial transmitters. Functionalities, architecture and technologies of such systems are described in ETSI TR 102 525 [18]. The physical layer of the radio interface (air interface) is divided up into the outer physical layer, the inner physical layer with a single carrier transmission, and the inner physical layer with multiple carrier transmission. It is specified by a set of standards consisting of ETSI TS 102550 [19], ETSI TS 102 551-1 [20] and ETSI TS 102 551-2 [21]. The reader is pointed to the references if more detail is required. The role of the Outer Physical Layer (OPL ) is to provide FEC and time interleaving for resistance against a variety of transmission channel conditions. Different transport channels are used in the OPL to offer the requested performance for different types of services. One special pipe exists whose functionality is to transmit all relevant parameters to decode the other pipes. The so-called signalling pipe is always transmitted at the lowest code rate which is $1 / 5$. The modulation of the signalling pipe is equal to the modulation of the data pipes. The Inner Physical Layer (Single Carrier) (IPL-SC) provides a robust modulation scheme for single carrier transmissions. The single carrier transmission is mainly applicable to satellite signal transmission but may be reused in other transmission environments. The Inner Physical Layer (Multi Carrier) (IPL-MC) provides a robust modulation scheme for multi carrier transmission. The multi carrier transmission is applicable either to satellite or terrestrial transmission. The IPL-MC is embedded between the OPL and the RF front end. Two types of IPL-MC exist: one providing a single-input interface, another providing doubleinput interface to allow hierarchical modulation. In the latter case, both inputs need to be aligned in time, framing and throughput. If more than one carrier needs to be supported, multiple cases of the IPL-MC need to be generated in parallel. To cope with different design constraints that arise from the possible use scenarios of the IPL-MC, it has been decided within SES SDR to define different profiles.

This specification does not restrict its use to these application scenarios. Other frequency bands or channel bandwidths may be used but the parameter selection may not be optimal. 
The DVB-SH documentation specifies the transmission system using ETSI Digital Video Broadcasting standards to provide an efficient way of carrying multimedia services over hybrid satellite and terrestrial (DVB-SH) networks at frequencies below $3 \mathrm{GHz}$. Target terminals include handheld (PDAs, mobile phones), vehicle-mounted, nomadic (laptops, palmtops) and stationary terminals. The following is a brief outline of DVB-SH. The reader is pointed to the references [22] and [23] for more detailed material.

The terrestrial repeaters may be of three kinds; (a) broadcast infrastructure transmitters which complement reception in areas where satellite reception is difficult, (b) personal gapfillers of limited coverage providing local on-frequency retransmission and/or frequency conversion; no local content insertion is possible, (c) mobile broadcast infrastructure transmitters creating a "moving complementary infrastructure". Depending on waveform configuration and radio frequency planning, local content insertion may be possible.

For the satellite, two modulations have been selected, which leads to two reference architectures within the variety of possible hybrid satellite/terrestrial systems architectures. These two architectures are both covered by DVB-SH and are described in the waveform document [23]. These are SH-A for OFDM terrestrial and OFDM satellite transmission mode and SH-B for OFDM terrestrial and TDM satellite transmission mode.

Other key points are (1) Two receiver classes: Class 1 receivers support short physical layer protection (in the order of one DVB-H burst). A long link layer interleaver complements this physical interleaver and is managed at service level, Class 2 receivers support long physical layer protection (in the order of several DVB-H bursts). This protection managed at channel level can be complemented by same link layer protection as class 1 receivers, (2) a highly flexible channel time interleaver that offers time diversity from about one hundred milliseconds to several seconds. This interleaver allows Class 1 receivers to co-exist with Class 2 receivers, within the same network, (3) Pilot symbols to make robust signal estimation and fast re-acquisition after a deep and long shadowing/blockage event for both TDM and OFDM modes. Implementation guidelines will provide more detailed discussions on system configurations features

\section{CONCLUSIONS}

SDMB and satellite delivery of mobile Digital TV is just becoming of age. Following comprehensive research and standards preparation systems are now being planned to provide services foreseen to be available in the next $2-3$ years.

\section{ACKNOWLEDGMENTS}

The authors wish to acknowledge the SatNEx Network of Excellence which supported activities relating to the material presented in this paper

\section{References}

[1] K.Narenthiran, M.Karaliopoulos, B.G.Evans, et al; "S-UMTS access network for broadcast and multicast service delivery: the SATIN approach"; International Journal of Satellite Communications and Networking, Vol. 22, No. 1, pp 87-111; Jan.Feb. 2004.

[2] ETSI TR 102 525: " Satellite Earth Stations and Systems (SES); Satellite Digital Radio (SDR) service; Functionalities, architecture and technologies, Technologies for the radio interface."

[3] SH System V1.5.doc: "Draft: System Specifications for Satellite services to Handheld devices (SH) below $3 \mathrm{GHz}$ ", Available to DVB Members at dvb.org

[4] Campanella S. J. "Seminar on the Worldspace Satellite Direct Digital Audio Broadcast System”, IEE Seminar, 19 July 1998

[5] Richard A. Michalski, "An Overview Of The XM Satellite Radio System", AIAA 2002

[6] Davarian, F.; "Sirius Satellite Radio: Radio entertainment in the sky"; IEEE Aerospace Conference Proceedings; March 2002.

[7] Lee S. "Satellite DMB in Korea" International Workshop for B3G/4G satellite Communications, Korea, 18 November 2004

[8] http://www.mobaho.com/english/index.html

[9] http://www.mbco.co.jp/english/03_news/news archive/050727_02. $\underline{\mathrm{html}}$

[10] http://www.worldspace-

europe.eu/press/Viatis\%20Sodielec\%20English\%20text.doc

[11] Kuhlen H, "Archimedes/MediaStar - provision of digital audio and data broadcasting services via satellite to mobile and fixed subscriber", Proceedings of the Digital Audio Broadcasting Conference, London, 6 \& 7 July 1995.

[12] http://www.tvconferences.com/dars/pres/singarajah1.pdf

[13] http://www.ondasmedia.com/

[14] ANFR "Presentation of the NEMO system", ECC JPT MSS $2 \mathrm{GHz}$ 30 November -1st December 2004, Brest, France (restricted to ECC members)

[15] Piero Angeletti, Riccardo De Gaudenzi, Rita Rinaldo, "Study of a Satellite Multimedia Broadcasting Mobile System Mission for the European@BUS Platform”, Paper, AIAA 2006-5479, 24th AIAA International Communications Satellite Systems Conference (ICSSC), 11 - 14 June 2006, San Diego, California

[16] http://www.eutelsat.com/news/compress/en/2006/pdf/PR\%205006 \%20Solaris.pdf

[17] $\underline{\text { http://ist- }}$

maestro.dyndns.org/MAESTRO/pages/Publication/ftp/MAESTRO/ Publication/MAESTRO $\% 20$ contribution $\% 20$ to $\% 20$ brochureJune $\% 2030$.doc?PHPSESSID $=6$ ce $9 \mathrm{~b} 1 \mathrm{~b} 149 \mathrm{~d} 28251207 \mathrm{~b} 3 \mathrm{f} 8 \mathrm{a} 67 \mathrm{~b} 73$ $\underline{7 e f}$

[18] ETSI TR 102 525: " Satellite Earth Stations and Systems (SES); Satellite Digital Radio (SDR) service; Functionalities, architecture and technologies, Technologies for the radio interface."

[19] ETSI TS 102 550: "Satellite Earth Stations and Systems (SES); Satellite Digital Radio (SDR) Systems; Outer Physical Layer of the Radio Interface ".

[20] ETSI TS 102 551-1: "Satellite Earth Stations and Systems (SES); Satellite Digital Radio (SDR) Systems; Inner Physical Layer of the Radio Interface Part 1 - Single Carrier Transmission".

[21] ETSI TS 102 551-2: "Satellite Earth Stations and Systems (SES); Satellite Digital Radio (SDR) Systems; Inner Physical Layer of the Radio Interface Part 2; Multiple Carrier Transmission".

[22] SH System V1.6.2.doc: "Draft: System Specifications for Satellite services to Handheld devices (SH) below $3 \mathrm{GHz}$ ", Available to DVB Members at dvb.org

[23] SSP0163r4_SH_Waveform_20070114r4.doc: Draft: "Framing Structure, channel coding and modulation for Satellite Services to Handheld devices (SH) below $3 \mathrm{GHz}$ ", Available to DVB Members at dvb.org

[24] 3GPP2 C.S0002-D: "Physical Layer Standard for cdma2000 Spread Spectrum Systems, Release C", http://www.3gpp2.org/Public html/specs/C.S0002D v2.0 051006.pdf

[25] ICO Selects Alcatel-Lucent and Hughes for Alpha Trial, ICO press release 2 May 2007

http://investor.ico.com/ReleaseDetail.cfm?ReleaseID=240320 